\title{
LAS HUELLAS DE LA MISIÓN ANDINA EN LAS COMUNIDADES INDÍGENAS DE CHIMBORAZO
}

\author{
Ph. D Luis Alberto Tuaza
}

\section{RESUMEN}

El ensayo analiza la memoria histórica de las comunidades indígenas sobre la intervención de la Misión Andina y los cambios sociales, identitarios y políticos que generó este organismo de cooperación en las décadas de los cincuenta y sesenta del siglo pasado. Asimismo, señala la emergencia de las mujeres indígenas en la vida comunitaria y organizativa como fruto del trabajo de la misión, a través de las misioneras Lauritas. El método que se aplica en esta reflexión es la etnografía, en base a las técnicas de entrevistas a profundidad a los miembros comunitarios, hombres y mujeres beneficiarios de los programas de desarrollo promovidos por la mencionada agencia de desarrollo.

Palabras clave: cooperación, transformación social y mujeres indígenas.

\begin{abstract}
The essay analyzes the historical memory of the indigenous communities about the intervention of the Andean Mission and the social, identity and political changes that this cooperation organism generated during the 50's and 60's in the last century. In the same way, it points out the emerging of Indigenous women in the community and organizational life as a result of the mission's work, through Lauriat's missioners. The method applied in this reflection is ethnography, using the technique of profound interviews to community members, men and women who benefited from the development programs promoted by the above mentioned development agency.
\end{abstract}

Key words: cooperation, social transformation, Indigenous women

Recibido: Abril, 2013

Aprobado: Junio, 2013

\section{Introducción}

El presente ensayo analiza las huellas de la Misión Andina en las comunidades indígenas cercanas a la ciudad de Riobamba de la Provincia de Chimborazo, después de sesenta años de su intervención, tomando como base los diversos testimonios de los actores que participaron en los programas ejecutados por esta institución de cooperación. Las preguntas a las que se responderá a lo largo de este análisis son las siguientes: ¿Qué se acuerdan los miembros comunitarios sobre la Misión Andina? ¿Qué reacciones tuvo en las comunidades? ¿Qué disputas generó la Misión Andina?¿Cuáles fueron los programas ejecutados por la Misión Andina y qué cambios generó en las comunidades? ¿Qué pasó con las mujeres? De entrada se señalan los recuerdos que los miembros comunitarios conservan de la Misión Andina, en un segundo momento se describen las disputas y los cambios que generó la intervención de la Misión y en un tercer momento se estudia la vinculación de la Misión Andina con las mujeres. 


\section{Recuerdos de la Misión Andina en las comunidades}

Han pasado más de sesenta años, desde que por primera vez las comunidades indígenas aledañas a la ciudad de Riobamba, recibieron la intervención de la Misión Andina, un programa de desarrollo del gobierno nacional dirigida a las poblaciones indígenas, con la participación de varias agencias especializadas de las Naciones, coordinadas por la OIT(UNESCO, FAO, OMS, UNICEF, Junta de Asistencia de las Naciones Unidas, Administración de la Asistencia Técnica de las Naciones Unidas) (Bretón 2001) que tenía por finalidad "la incorporación de la población indígena a la comunidad nacional activa, ayudándole a mejorar sus condiciones laborales, económicas, sociales y culturales" (Mencías 1962: 79).

Las comunidades donde intervino la Misión Andina, eran la mayoría anejos libres, vinculados en parte con la hacienda y que mantenía estrecha relación con los centros parroquiales, ya sea por el control político, religioso y festivo (Tuaza 2009). Comunidades que al decir del Padre Jorge Mencías, coordinador del Comité Ejecutivo de Integración del Campesino a la Vida Nacional de la Misión Andina, atravesaban retraso, miseria, analfabetismo, eran víctimas del alcoholismo... y que requerían acciones inmediatas que permitan integrarse a la vida nacional civilizada (Mencías 1962).

En la mayoría de las entrevistas que he podido realizar se constata que conservan los recuerdos de la Misión Andina como la institución del gobierno que construyó la escuela, los tanques de agua, el sistema de agua entubada, las letrinas y los puentes, promovió la creación de las escuelas en cada comunidad, capacitó a las maestras y maestros de las escuelas, formó a los dirigentes de las comunidades y técnicos comunitarios en el manejo de los telares, cerrajería y artesanías; entregó las plantas de los eucaliptos, pinos y ciprés, fomentó la crianza de los conejos, cuyes y borregos merinos, impulsó la siembra de hortalizas y papas, maíz y arvejas, de mejor calidad, introdujo el uso del abono químico a los suelos (Tuaza 2009).

Recuerdan también que la Misión Andina capacitó a las mujeres en bordados, tejidos, cursos de cocina, en socio dramas, el baile en el caso de las mujeres de La Moya. Algunas de las jóvenes indígenas fueron a participar en los cursos de prime- ros auxilios en Guaslán y en Ibarra, otras fueron llevadas por las Misioneras Lauritas a Riobamba, a estudiar la primaria y aprender las "buenas" costumbres de la ciudad.

Asimismo, conservan el recuerdo de la Misión Andina, como la institución que organizó los encuentros deportivos en las comunidades, a través de los campeonatos. Al respecto, Pedro Shisha de la Comuna La Moya, señala: "Con la Misión Andina aprendimos a jugar el voly y el futbol. Los técnicos de esta institución nos llevaban a Gatazo, Guano, Guabug, Chimborazo, San Francisco, Nitiluisa, Guaslán y Batzacón".

Recuerdan también como con la Misión Andina, las mujeres aprendieron nuevas formas de cocinar, tal como sostiene María Puma de Jatari Campesino, "con la Misión Andina aprendimos hacer las tortillas". Pero al mismo tiempo, aprendieron nuevas formas de relacionarse con los mestizos. En este sentido, María Natividad Buñay de Rumicruz, señala: "Con la Misión Andina llegamos a saber que a los mestizos no había que saludar diciendo bendito y alabado o sacramento amito, sino buenos días y buenas tardes".

Los hombres de las comunidades de La Moya, Jatari Campesino, Gatazo Chico, Nitiluisa señalan que con la Misión Andina aprendieron a sembrar nuevos cultivos, en parte similar a los productos que había en las comunidades: así recibieron semillas de papas, maíz, arveja, y por otra parte, cultivos foráneos al medio como son las coles, coliflor, la cebolla paiteña, culantro, remolacha y zanahoria. Asimismo recibieron las semillas de pasto, con los que introdujeron la siembra de los potreros.

Las mujeres y los hombres, especialmente de La Moya se acuerdan que la Misión Andina entregó borregos de la raza rambouillet de Pachamama que crecía rápido, daban la lana de mejor calidad, producían mucha carne y tenían un valor elevado en el mercado. En esta perspectiva, Mariana Miñercaja y Vicenta Miñercaja sostienen: "nuestros borregos eran pequeñitos, bastos. En la plaza nadie quería comprar o sino compraban a precios bajos. Vino la Misión Andina y puso buenas ovejas". Por su parte, Esteban Miñercaja señala, "Los borregos de la Misión Andina eran de buena calidad que vendíamos al precio de 70 a 80 sucres cada uno". A decir del mismo Esteban Miñercaja, no solo recibieron de la Misión Andina los borregos, sino también ganado vacuno de mejor 
calidad.

De la Misión Andina se acuerdan también que con esta institución vinieron las Misioneras Lauritas a las comunidades a dar a las mujeres cursos de tejidos, socio dramas, el baile y el rezo. Ana Ajitimbayy María Toaza recuerdan que ellas por la Misión Andina se fueron a vivir en el Hogar Indígena Nuestra Señora de Guadalupe dirigida por las Misioneras Lauritas en Riobamba.

Se acuerdan también que la Misión Andina entregaba las raciones alimenticias de sémola, arroz de trigo, frijol, enlatados, aceite para estimular la participación colectiva en las mingas. En este sentido, Isabel Sisa recuerda, "La Misión Andina entregaba los alimentos para animar a la gente para que vayan a las mingas. Con el gusto de ir a coger los alimentos, casi todos acudíamos a las minga, porque los alimentos se recibían de acuerdo al número de las rayas".

Algunas mujeres como María Puma se acuerdan que con la Misión Andina vino para las mujeres indígenas la oportunidad de estudiar, de asistir a la escuela. "Antes sólo los hombres podían ir a la escuela. Nuestros padres consideraban que no era necesario para las mujeres conocer la letra, basta saber pastar a los chanchos y a las ovejas, saber cocinar" señalan Vicenta Miñercaja, Mariana Miñercaja y Petrona Ati. Con la Misión Andina, algunas mujeres fueron a estudiar en la escuela, y tuvieron la oportunidad de concluir la primaria.

Se acuerdan también que con la Misión Andina llegó la costumbre de elegir a los miembros del cabildo (Hurtado y Herudek 1974). Hasta los años cincuenta del siglo pasado en la mayoría de los anejos libres cercanos a Riobamba, los curas párrocos y los apus de los pueblos designaban al regidor (Tuaza 2011), a su vez, el regidor como en el caso de La Moya elegía a sus alcaldes_alcalde mayor y menor_. El regidor junto con los alcaldes, tenían la autoridad de velar por la vida comunitaria, exigía a los miembros comunitarios a asistir a la doctrina, bajo la guía de los apus elegían los priostes de la distintas fiestas religiosas que se celebraban en los centros parroquiales. Al respecto Isabel Sisa de Rumicruz sostiene, "antes que venga la Misión Andina no había el cabildo, sólo había el regidor y los alcaldes. El regidor era elegido por el cura el jueves después de carnaval, e inmediatamente arrodillándose delante del cura el regidor prometía desempeñar sus funciones ante la comunidad y el pueblo. Desde la Misión Andina hay el cabildo que es elegido por la comunidad".

Sin duda, los puentes, en el caso de La Moya, las escuelas, en la mayoría de las comunidades y los eucaliptos, traen inmediatamente a la memoria sobre la presencia de la Misión Andina en las comunidades. En los anejos donde se conserva el kichwa, la indumentaria indígena es más fácil encontrar con recuerdos detallados de las acciones realizadas por la Misión Andina, mientras que en las comunidades donde se ha perdido el kichwa, escasamente se puede encontrar con la información detallada de todo lo que hizo la misión.

La mayoría de las escuelas construidas por la Misión Andina, pese al correr de los años se mantienen intactas. En la restauración que se ha hecho de estos establecimientos, han cambiado el techo de teja por eternit y lógicamente la pintura. Pero las paredes, los cuartos, los baños, la cocina permanecen tal como fueron construidos hace cincuenta años.

Casi todas las escuelas de la misión están diseñadas con un cuarto, la sala grande de estudio y un corredor, al frente se puede encontrar con el altar patrio donde los días lunes se coloca la bandera del Ecuador y de la provincia. En el pasado, como casi todas las escuelas del sector rural eran unidocentes se requería de un solo salón de clases donde el profesor impartía sus conocimientos a todos los grados. El cuarto a su vez, servía de vivienda del profesor/a que permanecía en la escuela durante toda la semana y una cocina de leña y un baño en la parte lateral. Hoy en día, estos cuartos sirven de aulas de algún grado.

\section{Reacciones que provocó la Misión Andina en las comunidades}

La presencia de la Misión Andina en los anejos cercanos a Riobamba, provocó el temor, por cuanto que se creía que el gobierno nacional se apoderaría de las tierras. Al respecto la mayoría de los entrevistados señalan, "tuvimos miedo de coger las plantas de eucalipto, porque se nos decía que el gobierno nos va a quitar nuestras tierras".

Hubo comunidades como el caso del Socorro que pidieron la intervención inmediata de la Misión Andina para la construcción de la escuela, pero pronto los miembros empezaron a dudar y decidieron rechazar la construcción. En este sentido, Don Pablo Sani, quien desempeñó las funciones 
de vocal en ese tiempo señala, "hubo un hombre de mal corazón que puso las dudas en la gente, por lo que ya no querían venir a trabajar y a colaborar".

Con respecto a la escuela, particularmente con la tarea de enviar a los hijos a las clases, muchos de los miembros comunitarios, tenía el temor, que una vez sus hijos hayan alcanzado la primaria, el gobierno les lleve al cuartel y que convierta en soldados. "había mucho miedo, nuestros padres y familiares no querían que asistamos a la escuela, porque se pensaba que el gobierno llevaría a ser soldados", opinan los moradores de La Moya. Vistos desde este tiempo, este temor era promovido por los mestizos de los pueblos y los cantineros que veían como una amenaza el estudio de los niños indígenas, porque creían que una vez concluidas la primaria y la secundaría, de alguna manera, empezarían a cuestionar la situación de explotación a la que estaban sometidos sus padres; y el control en el consumo de la chicha representaría los bajos ingresos económicos para los cantineros.

El miedo, la inseguridad que sentían los comuneros a la Misión Andina, no sólo provocó el rechazo de esta institución, a decir de Pedro Llangarí de San José de Gaushi, "hizo perder muchas oportunidades, la posibilidad de contar con un buen sistema de agua entubada desde la hacienda de los Cordobés", una de las familias aristocráticas de Riobamba (Sylva 1980). En efecto, la comuna San José de Guashi perdió el agua de la fuente de los Cordobés que está situada a $2 \mathrm{~km}$ de la comunidad. El actual sistema de agua potable que tiene esta comuna, viene de Tambowasha, de una distancia de $16 \mathrm{~km}$.

La acción de la Misión Andina de incorporar a las mujeres al mercado y a la educación, por medio de los cursos de tejidos, bordados, la asistencia a la escuela y el ingreso al Hogar Nuestra Señora de Guadalupe trajo resistencias en ciertos padres de familia que sentía que sus hijas se alejaban del hogar, asumían nuevas costumbres ajenas al medio, empezaban a reaccionar contra la autoridad de los progenitores, aprendían la letra y con esto se hacían resabiadas y semejantes a los hombres.

No obstante, ciertos dirigentes que trabajaron y fueron formados por la Misión Andina, vieron que esta institución les daba la oportunidad a las mujeres de superarse. Este es el caso de Valentín
Puma, presidente del cabildo de La Moya (1958) que animaba a su hija María Puma a estudiar y a participar de todos los programas que realizaba la Misión Andina, a través de la presencia de las Misioneras Lauritas. "Mi papacito no me impedía participar, al contrario me exigía prepararme", dice María Puma. Otro caso similar fue el del dirigente de Pisicaz, Manuel Ajitimbay que fue a dejar a su hija Ana en el Hogar Nuestra Señora de Guadalupe de las misioneras Lauritas, movido por su ideal de ver a su hija preparada y distinta al resto de las chicas de la comunidad.

La presencia de la Misión Andina fue vista también como la infiltración de los gringos a las comunidades (Tuaza 2011). En la opinión de algunos entrevistados "con la misión vinieron los gringos". Estos fueron vistos como aquellos que vienen a sacar información y como personas que con el tiempo podía adueñarse de las tierras. Pero pronto cambio estos imaginarios en la medida en que vieron que los gringos se comprometían con el trabajo y enseñaban nuevas técnicas.

En ciertos casos la Misión Andina fue considerada como una institución que promueve la llegada del protestantismo religioso a las comunidades (Andrade 2004), por la que algunos miembros comunitarios resistieron participar de los programas y en el caso de los moradores de San José de Guashi rechazaron la intervención de la Misión Andina. Para evitar estas consideraciones, desde la misión diseñaron la estrategia de realizar las misiones populares en los anejos.

Así, antes de la llegada de la Misión Andina, los padres redentoristas de Riobamba, hicieron las misiones en el Socorro y alentaron a recibir las ayudas que traía esta institución. "Los padres de Loja vinieron a decir que hay la oportunidad de conseguir ayuda, que cojan nomás", señala Pablo Sani.

En los casos de Guabuc, Gatazo Grande, el Hospital y La Moya, la intervención de la Misión Andina estuvo presidida por las misiones populares de las Misioneras Lauritas. La misma estrategia fue utilizada en las comunidades Sanguisel Alto, San Bernardo, San Martín de la parroquia Columbe, tal como sostiene Petrona Ati: "Antes de que trabaje la Misión Andina, las monjitas Lauritas realizaban las misiones. Este era el primer paso, así hicieron en Guabuc y en otras comunidades. Cuando yo fui a Sanguisel ahí ya habían estado las Lauritas". 
Con las misiones populares de los padres redentoristas y especialmente de las Misioneras Lauritas, los directivos de la Misión Andina demostraban a las comunidades que no tenían nada que ver con los evangélicos $u$ otro grupo religioso sino que eran católicos y para expresar la estrecha vinculación de la institución con la iglesia católica llevaban a Mons. Leonidas Proaño, Obispo de Riobamba a bendecir las escuelas y otras obras ejecutadas por la misión.

No se puede dudar de esta relación de la Iglesia Católica y la Misión Andina, el coordinador de esta institución P Jorge Mencías, a decir del Padre Modesto Arrieta, "fue puesto por Mons. Proaño", versión que coincide con la opinión de Homero García. Por otro lado, las misioneras Lauritas eran parte del personal de la Misión Andina (Mencías 1969: 146) y alrededor del trabajo de esta institución dieron inicio a un nuevo estilo de trabajo pastoral que provocaría de alguna manera la ruptura con el centro parroquial, dando paso a que la comuna se convierta en el centro ceremonial.

Por otra parte, la Misión Andina fue vista por los miembros de los anejos cercanos a Riobamba como la institución que viene a ayudar a los indígenas a salir de la pobreza y la miseria. "Con la Misión Andina hubo buenas oportunidades, pero no entendíamos" manifiesta Petrona Ati. "Con la Misión Andina mejoramos nuestros cultivos, sembramos nuevas semillas, llegamos a tener buenos borregos, cuyes y conejos" señala Esteban Miñercaja. "Las mujeres por primera vez empezamos a conocer la letra, a acudir a la escuela. Desde ahí, poco a poco los padres aprendieron mandar a sus hijas a la escuela" sostiene Vicenta Miñercaja.

La construcción de las casas fue una de las obras que provocó resistencias en las comunidades. En principio, la Misión Andina no construyó las casas para todos los beneficiarios de las comunidades. "En Guabuc construyeron dos casas", señala Petrona Ati. La misión construyó dos o tres casas como demostración para que los otros comuneros inmediatamente procedan a construir casas similares rechazando para esto sus antiguas chozas. Pero la reacción fue distinta: no siguieron el modelo de construcción diseñada por la Misión Andina, los comuneros continuaron prefiriendo sus chozas, aún los mismos beneficiarios de las casas continuaban viviendo en la casa tradicionalmente construida. En este sentido, $\mathrm{P}$ Modesto Arrieta y Homero García sostienen que los indígenas en vez de habitar en las casas de ladrillo y de teja, pusieron a los animales y siguieron en sus chozas. La Hermana Isabel Fonseca, misionera Laurita, por su parte, manifiesta que el proyecto de "las casas fue un fracaso, porque una vez que la Misión Andina terminaba su intervención, al regresar a las comunas encontraron que las ventanas grandes de las casas habían sido cerradas".

En el periodo en que se ejecutó la Misión Andina y en el marco de las misiones populares realizadas por las Misioneras Lauritas, varias chicas indígenas de las comunidades fueron llevadas al Hogar Nuestra Señora de Guadalupe de Riobamba, bajo la dirección de las mencionadas misioneras, una obra cuyo propósito era de ser "un centro de formación integral para las jóvenes indígenas en el que eleven su nivel de cultura, al mismo tiempo asimilen mejores hábitos de vida, enciendan en su alma deseos de mejorar su tristeza humana traducida a concretos propósitos (...) que sean después las protagonistas de la mejora de su raza, mejora igualmente concebida de un modo integral" (Mencías 1962:148). En términos generales un hogar en el que "aprendan a vivir mejor: en el vestido (que sea acomodado a las inclemencias de los páramos en que viven), en la alimentación (que sea suficiente), en la vivienda (que sea para seres humanos y no para alimañas)". Se aspira a que "sirvan a sus comunidades como catequistas, auxiliares en el trabajo de campo, auxiliares de enfermería y parteras" (Mencías 1962:148).

De la permanencia en esta casa señala María Lata, "las madres nos enseñaron la letra, dieron cursos de primeros auxilios, enseñaron a cocinar, a hacer fideos, tortas y dulces". Ana Ajitimbay, por su parte sostiene, "sí aprendí la letra y la manera de curar a los enfermos, poner inyecciones, los rezos pero la vida ahí era como la del cuartel. Nos levantábamos a las dos de la mañana a hacer el pan, a lavar la ropa. Las monjitas no hacían caso lo que habíamos lavado y planchado, tiraban la ropa al tanque y como no teníamos piedra para fregar, entonces nos arrodillábamos en el piso de cemento". María Lata coincide con este testimonio, al afirmar que "sí sufríamos mucho, era mucho maltrato, nos trataban peor que a esclavas".

Esto demuestra que la asimilación de los mejores hábitos de la vida, la incorporación a la vida nacional y convertirse en las protagonistas de las mejoras de su raza (Tuaza 2010) tuvo un costo alto para las mujeres indígenas, hasta tal punto que regresaban a sus comunidades y no encontraban posibilidades de convertirse en auxiliares 
de enfermeras u otro oficio, no habían terminado la instrucción primaria, y al mismo tiempo, supuso problemas en el proceso de reincorporación a la comuna indígena. "Aprendí la letra, pero regresé sin nada a la casa, sin saber qué hacer. Hubo promesas de días mejores, pero no llegó, tenía que regresar con la misma cara a la casa de mis padres", sostiene María Lata. En esta misma perspectiva considera Ana Ajitimbay, "aprendí algunas cosas de enfermería y rezos que luego me sirvió, pero tuve que regresar a la casa y más bien en la comuna aprendí sobre la organización y empecé a trabajar por los demás". María Sisa, madre de María Lata señala, "mi hija tuvo muchos problemas cuando regresó de las monjas, sufría mucho en la comida".

\section{Los cambios generados por la Mi- sión Andina}

Sin lugar a dudas, la intervención de la Misión Andina produjo cambios significativos para aquel tiempo: se crearon las escuelas en todos los anejos y la educación empezó a ser gratuita. "Antes los niños tenían que ir a San Vicente, tenían que pagar un sucre mensual, con la Misión Andina se creó esta escuela" manifiestan los moradores de la comuna La Moya. Además, con esta institución de cooperación las mujeres empezaron a estudiar y a asistir a la escuela, así lograron romper con la consideración tradicional de que "las mujeres sirven solo para pastar borregos, puercos, cocinar, lavar y cuidar la casa".

Con la Misión Andina se implementó la posibilidad para los jóvenes indígenas de estudiar la secundaria fuera de sus anejos, en otras provincias. Según Ángel Chimbo, "la Misión Andina entregó a los jóvenes la beca completa a los pobres y media beca a los hijos de indígenas pudientes". Esto permitió que en caso de los jóvenes de Nitiluisa estudiaran en San Miguel de Chimbo y en Pujilí, y se convirtieran más tarde en profesores de escuela y en ciertos casos continuaran con la formación universitaria como fue el caso de José Paucar que se convirtió en el primer abogado indígena de Calpi.

Los cursos de tejidos y bordados dieron a las mujeres indígenas las posibilidades de diversificar la producción y tecnificar los antiguos tejidos de la shigras con cabuya, al mismo tiempo, la misión introdujo nuevas prácticas alimenticias, el consumo de sémola, la harina flor, el arroz de trigo, los enlatados, el aceite en vez de la masha, las sopas de arroz de cebada y las coladas de maíz, nuevas formas de preparar los alimentos, la tortilla, los dulces, las tortas, el pan, el baile y la presentación de socio dramas y los cursos de primeros auxilios.

Mujeres como Petrona Ati tuvieron la posibilidad de hacer los cursos de enfermería en Guaslán e Ibarra e incorporarse como personal de la Misión Andina para atender a las comunidades y trabajar en Ibarra y en el hospital de Riobamba, aunque esta experiencia duro muy poco, porque a decir de Ati, "contrataron por poco tiempo y luego ya no me llamaron" y a esto se une los impedimentos que puso su familia, especialmente el esposo, pero considera que ha servido mucho para ella, hasta tal punto que recientemente prestó sus servicios en el Hospital Andino de Riobamba.

La implementación del sistema de agua entubada, la construcción de pozos de agua, tanques para lavar y bebederos de animales fue un aporte importante de la Misión Andina a las comunidades. Por primera vez, los indígenas vieron llegar a sus anejos y en ciertos casos, a sus casas el agua en tubería. Con esto quedaron en el olvido los antiguos sacrificios de ir al pugyo, de coger el agua en las quebradas a varias distancias de la casa. "Con el agua de llave, se acabó el sufrimiento de ir a traer el agua de la quebrada", señala Isabel Sisa. En comunidades como San Martín (Columbe), hasta nuestros días conservan los pozos y los tanques construidos por la Misión Andina. Las comunidades de La Moya y Nitiluisa conservan la tubería y los tanques de la misión con pocas modificaciones.

La Misión Andina dentro de su programa agropecuario que buscaba "aumentar la productividad de la tierra y mejorar, diversificar y comercializar los productos agrícolas y pecuarios" (Mencías 1962:79), implementó la siembra de árboles de eucalipto, pinos y ciprés, entregó las semillas de papas, maíz, arveja y hortalizas, fomentó la cría de borregos de buena raza, conejos y cuyes. Con estos aumentó la producción y al mismo tiempo permitió a las familias indígenas mejorar sus ingresos económicos. "Cuando íbamos a vender a nuestros pequeños borreguitos, nadie quería comprar, los pagos eran mínimos, pero con los borregos merinos de la misión llegamos a vender en 70 sucres, hasta 80 sucres cada uno" manifiesta Esteban Miñercaja. Obviamente para la época representaba un buen precio.

La actividad agropecuaria fue vista por la misión 
como una tarea propiamente de los hombres. Quienes participaban de las tareas demostrativas, los cursos de agricultura, la construcción de jaulas de conejos, el manejo de los borregos y el cultivo de los huertos eran generalmente hombres. "Con la misión aprendimos a crear los conejos en jaula, a tener buenos borregos, buenas vacas y buenos cultivos" sostienen los hombres entrevistados en Gatazo Chico, La Moya y Rumicruz.

Como se ha señalado en los acápites anteriores, la Misión Andina introdujo la siembra de los árboles de eucalipto, pino y ciprés. Para aquel tiempo, estas especies, particularmente el eucalipto fue novedoso, por cuanto proporcionaban la madera y permitían tener la leña suficiente para la cocina. "Antes de tener el eucalipto sólo teníamos la paja de la cebada, los pencos secos de la cabuya y los tallos secos de los espinos para cocinar" expresa Clemente Cayambe de Batzacón. En efecto, hasta los años noventa del siglo pasado, los hogares indígenas no utilizaban la cocina a gas, dependía de la leña proporcionada por el eucalipto y por otro lado, el combustible obtenido de este árbol permitió poner límites al corte del pajonal. No obstante, en la actual valoración de este árbol muchos consideran que el eucalipto maltrata el suelo y con el tiempo ocasiona la erosión de la tierra.

Asimismo, la Misión Andina introdujo la idea sobre la importancia de los cursos de capacitación, tanto para las labores agrícolas y pecuarias como para la vida familiar y comunitaria (Bretón 2001). Al respecto, casi todos los entrevistados afirman que con los cursos aprendieron nuevas técnicas, mejoraron la producción, conocieron nuevas experiencias de manejo del ganado y el cultivo de nuevas especies, aprendieron a tejer en los telares, la carpintería y la cerrajería.

En el caso de las mujeres aprendieron a tejer suéteres, el bordado de la camisa, los quehaceres de la cocina, el aseo y las formas de eliminar los parásitos. La Misión Andina en palabras de María Puma, "hizo los cursos de aseo, del uso de jabón y trajeron el polvo de matar a los piojos y pulgas".

En términos políticos y organizativos, la presencia de la Misión Andina provocó el declive de los poderes tradicionales que estaban en las manos de los tenientes políticos, el cura párroco y los apus del pueblo, dando paso así a lo que Casagrande y Piper (1969) consideran "la transformación estructural" de los poderes locales. Por otro lado, introdujo la costumbre de elegir por votación po- pular al cabildo al inicio del año nuevo o en su defecto, los últimos días del mes de diciembre. Con la elección popular, la comuna elegía a sus representantes. De este modo se rompió con la tradición de regidores elegidos por los curas, y al servicio de los apus en muchos de los casos.

La instauración del cabildo permitió que los conflictos comunitarios sean resueltos en la misma comunidad y no ante el teniente político como tradicionalmente se había hecho (Carrasco 1993). La legítima autoridad sobre los miembros comunitarios, ya no estaba en el cura, el teniente político y en los mestizos de los pueblos, sino en el cabildo elegido por todos los hombres que representaban a cada una de las familias (Lentz 1986).

Si los regidores y sus alcaldes eran constituidos en orden a los ritos ceremoniales religiosos, la obediencia a ciertos apus pueblerinos, el deber de convocar a la doctrina, velar por la sana convivencia familiar, la resolución de pequeños conflictos familiares y la de convocar a los miembros a barrer las calles de los pueblos y el arreglo del cementerio (Lentz 1986). Con la influencia de la Misión Andina, el cabildo se institucionalizo como el ente representativo de cada una de las comunidades ante el Estado, asumió la tarea de gestionar los recursos para las obras comunitarias y la implementación, llamémoslo así, de políticas públicas y en las palabras de Isabel Sisa "acabó con las doctrinas y las obligaciones de ser priostes".

Si bien es cierto que con la Misión Andina se implantó la elección popular, no obstante en el caso de las mujeres de los anejos indígenas cercanos a Riobamba, no podían elegir al cabildo, debido a que el voto y el derecho a ser elegidos estaban reservados a los hombres en cuanto a jefes de familia. Hasta los años noventa, no podemos encontrar en las comunidades jefas de familia. Las mujeres que de pronto quedaban viudas, no podían asumir el título de jefas de familia, la representación de la familia asumía el hijo mayor. Asimismo, las mujeres no podían asumir cargos de representación comunitaria. Hoy en día se ha superado estas situaciones: las mujeres pueden ser elegidas para presidir el cabildo de la comunidad u otros cargos.

La intervención de la Misión Andina permitió el establecimiento de redes de dirigentes: así Mariana Miñercaja de La Moya sostiene, "con la Misión Andina se establecieron contactos, se hicieron amigos entre los dirigentes. Mi papá tenía amis- 
tad con Pedro Celestino Paucar, Cecilio Paucar y Evaristo Cucurí de Nitiluisa, Esteban Agualsaca en San Francisco, en Palacio Real: Manuel Acalo y Darío Acalo. Ellos han sido los amigos y gestores de las obras en esta zona". En los años posteriores, tomando el testimonio de estos dirigentes, los cabildos de las comunidades de Calpi promovieron la creación de la Unión de Comunidades Indígenas de Calpi, hoy, Corporación de Comunidades Indígenas de Calpi.

Junto con la emergencia de los cabildos, las comunidades empezaron a tener autoridad sobre sus miembros (Tuaza 2011). Los conflictos se resolvieron dentro de la comuna y los ritos religiosos: la fiesta y la misa, empezaron a celebrarse en las comunas. Esto, porque la Diócesis de Riobamba en el trabajo conjunto con la Misión Andina llegó a comprender que era necesario atender a las poblaciones indígenas en su propia jurisdicción (Mencías 1962). Con esto ya no era necesario ir a escuchar misa en el pueblo, pasar la fiesta religiosa en la iglesia parroquial, sino el coordinador de la Misión Andina u otro sacerdote, incluso el mismo párroco celebraba las misas en los anejos donde se ejecutaban los programas de la misión y las fiestas se podían celebrar comunitariamente, sin obligar a que el prioste venda los terrenos para los gastos de las fiestas, tal como sucedía en el pasado (Mencías 1962:127-134).

Con la Misión Andina, de alguna manera, empezó el declive de "las relaciones asimétricas" (Burgos 1979) entre indígenas y mestizos, dando paso a una relación de igual a igual, al menos en los imaginarios indígenas. "La Misión Andina nos enseñó a no seguir saludando a los mestizos con la frase "sacramento amito", sino buenos días y buenas tardes" manifiesta María Natividad Buñay.

Por otra parte, los campeonatos de futbol y voley organizado por la Misión Andina permitió la integración de las comunidades. Hoy en día, la realización de los campeonatos es común en las comunidades donde intervino la Misión Andina. "Los técnicos de esta institución nos enseñaron a jugar, llevaron a jugar en Guabuc, Gatazo, Guano y otros lugares" señala Pedro Shisha de La Moya.

Los cursos de telares, la carpintería y cerrajería diversificaron al trabajo agropecuario de los indígenas y ofrecían nuevas alternativas de generar ingresos económicos. Sin embargo, pocos se especializaron en el manejo de los telares y en los oficios de carpintero y cerrajero. Pero en caso de estos dos últimos oficios pronto fueron dejados, debido al costo de la materia prima y de las herramientas. En parte sucedió lo mismo con los telares. En las palabras de Ángel Chimbo, "los telares funcionaron mientras la misión ponía los materiales, pero cuando no hubo recursos económicos se acabó y la gente se peleó".

La construcción de puentes y la apertura de caminos cambiaron sustancialmente la vida de las comunidades. Con la Misión Andina, los moradores de La Moya abrieron caminos anchos, terminando así con los antiguos chakiñany construyeron los puentes que libraron a la población de los peligros de las crecientes. Asimismo, por primera vez, vieron la llegada de un automóvil al centro comunitario.

La llegada de los técnicos extranjeros produjo admiración y temor de los miembros comunitarios. En el caso de los habitantes de La Moya era la primera vez que conocían a los gringos. "Con la Misión Andina vinieron los gringos" es el primer recuerdo que manifiestan los entrevistados de la mencionada comunidad. La admiración por los gringos fue tan grande que a los técnicos nacionales como al Sr. Jácome y Sr. Martínez confundían con los gringos, gringo Jácome y a los indígenas que acompañaban a estos les ponían el apodo de gringos. Este fue el caso del indígena Segundo Miñercaja a quien hasta nuestros días conocen con el apodo de "gringo Pashco".

De alguna manera, esto provocó cambios en el imaginario. El mundo ya no estuvo compuesto de indígenas y los mestizos, sino de otras culturas y otros saberes. Surgió la necesidad de apertura a otros pueblos y otras técnicas. Los gringos traían el carro, las películas...A diferencia de los mishus de los pueblos que comúnmente llegaban a explotar, los gringos venían a curar y a ofrecer su mano en los trabajos a favor del llamado desarrollo de los indígenas en su proceso de incorporación a la vida nacional.

\section{La relación de la Misión Andina con las mujeres indígenas}

Ni en los informes de septiembre de 1956 a mayo de 1957 preparado por David T. Luscombe, Jefe de la Misión Andina en el Ecuador, ni en el texto del P Mencías (1962), ni en los informes de los años 1966 a 1968 de las labores de los expertos de educación de la Misión Andina no aparece un programa específico dedicado a las mujeres. Es 
así como los programas de "organización de la comunidad, educación rural, salud y saneamiento, servicio social rural, fomento agropecuario, fomento artesanal, formación de líderes y adiestramiento de los técnicos, obras comunales y construcciones" (Gordillo 1966) a primera vista no tomaron en cuenta a las mujeres.

De acuerdo a los testimonios que he podido encontrar, la situación fue distinta. Como se ha detallado anteriormente, con la Misión Andina las mujeres entraron a la escuela, participaron en los cursos de tejidos, bordados y cocina, mujeres como María Lata y Ana Ajitimbay fueron al Hogar Nuestra Señora de Guadalupe de las misioneras Lauritas, Petrona Ati se preparó como enfermera. Aunque, pagaron un alto costo como fue el rechazo de los padres en el caso de María Lata y Petrona Ati y de maltrato en el hogar de las monjas en los casos de las señoras Lata y Ajitimbay. Sin embargo, la experiencia obtenida de la misión, preparó la incorporación de las mujeres en los procesos políticos y organizativos indígenas. Este es el caso de Ana María Guacho de la Comuna Guabug, fundadora del Movimiento Indígena de Chimborazo, formada por la Misión Andina.

Los programas de entrega de alimentos, los cursos de tejido y bordados, la introducción de animales de alta calidad y rendimiento _borregos merinos, cuyes, conejos_aumentaron la producción y mejoraron los ingresos económicos de la familia, permitiendo que las madres cuenten con recursos económicos para el cuidado y la educación de los hijos.

Aunque escasamente en los documentos se visibiliza la participación de las mujeres, en las entrevistas hace entrever que quienes participaron activa y mayoritariamente de los programas de la Misión Andina fueron las mujeres. En el caso de La Moya, según el testimonio de Vicenta Miñercaja para la ejecución de los programas de la Misión Andina y la construcción de la escuela lideró a la comunidad María Calapiña, una mujer que a decir de María Toaza "acompañó a los dirigentes y alentó a los moradores de La Moya a aceptar a la Misión Andina y pedir que haga obras".

Por otro lado, las mujeres participaron en las mingas y en la entrega de las colaboraciones para atender a los albañiles de la Misión Andina, tal como fue el caso de María Natividad Buñay y Lucía Concha. Al respecto señala María Natividad Buñay, "yo trabajé y puse una shigra de papas y un cuy para atender a los albañiles que construyeron el puente de la Misión Andina".

En cuanto al personal de la Misión Andina, si bien es cierto que aparece el protagonismo de los expertos extranjeros, los técnicos nacionales con sus auxiliares y obreros todos hombres, y escasamente se visualiza la acción de las mujeres como fue el caso de las Misioneras Lauritas que tuvieron el cargo de enfermeras y auxiliares de enfermería, y que trabajaron acompañadas de las alumnas de las Escuelas de Servicio Social de Quito (Mencías 1962, 94-96). No obstante en las bases, las Misioneras Lauritas, ocasionalmente ayudadas por las alumnas de las escuelas de servicio social, desempeñaron un rol fundamental en la intervención de la Misión Andina.

Las religiosas Lauritas entraron en contacto directo con los indígenas, vivieron meses con los indígenas en sus comunidades, realizaron las misiones populares, enseñaron los tejidos de suéteres y los bordados, impartieron los cursos de cocina, instruyeron en la realización de los socio dramas y los bailes, pero ante todo, fomentaron la confianza de los indígenas hacia la intervención de la Misión Andina. Sin embargo, se cuestionan los maltratos que ocasionaron a las internas indígenas en el Hogar Nuestra Señora de Guadalupe.

Sin la presencia de las Misioneras Lauritas, las alumnas de las escuelas de servicio social de Quito y ante todo la participación activa y comprometida de las mujeres indígenas de cada una de las comunidades, la intervención de la Misión Andina no hubiese tenido el impacto que logró alcanzar y ejecutar los diversos programas que se pusieron ad experimentumen los anejos cercanos a Riobamba y posteriormente se aplicaron en el resto del Ecuador, en el Perú y Bolivia.

\section{Conclusión}

La Misión Andina se convirtió en un aliado importante de los anejos indígenas cercanos a Riobamba en su proceso de fortalecimiento comunitario, en la consecución de los recursos técnicos y económicos, al mismo tiempo que permitió abrir las puertas a la modernización con la introducción de semillas, animales de mejor calidad, las obras de infraestructura, la creación de las escuelas, la dotación de agua entubada, los cursos y talleres artesanales y en la perspectiva política, la instauración de la elección popular para elegir a los miembros del cabildo, lo que posibilitó el debacle 
de los poderes tradicionales y la apertura a la democratización al interior de cada una de las comunidades. Posibilitó la participación de las mujeres en los procesos organizativos comunitarios y en los programas de desarrollo. Estas experiencias se convirtieron en el punto de partida para la presencia de los indígenas en la escena social y política del Ecuador.

\section{Bibliografía}

1. Andrade, Susana (2004). Protestantismo indígena. Procesos de conversión religiosa en la Provincia de Chimborazo, Ecuador. Quito: FLACSO.

2. Burgos, Hugo (1977). Relaciones interétnicas en Riobamba. México: Instituto Indigenista Interamericano.

3. Bretón, Víctor (2001). Cooperación al desarrollo y demandas étnicas en los Andes ecuatorianos. Ensayos sobre indigenismo, desarrollo rural y neoindigenismo. Quito: FLACSO.

4. Carrasco, Hernán (1993). "Democratización de los poderes locales". En sismo étnico en el Ecuador. Quito: CEDIME, AbyaYala.

5. Casagrande, Joseph y Piper, Arthur (1969). La transformación estructural de una parroquia rural en las tierras altas del Ecuador. En América Indígena.- Vol. XXIX, no. 4. Universidad de Illinois.

6. Gordillo, Miguel Ángel (1966). Misión Andina del Ecuador: informe $n \cdot 1$ del 1 abril -31 de mayo del 66. Quito: documento electrónico disponible en http:/www.unesdoc.unesco.org.

7. Hurtado, Osvaldo, Joachim Herudek (1974). La organización popular en el Ecuador. Quito: Inedes.

8. Luscombe, David (1957). Informe del periodo septiembre de 1956 - mayo de 1957presentado por el jefe de la Misión Andina en el Ecuador.

9. Lentz, Carola (1986). "De regidores y alcaldes a cabildos, cambios en la estructura socio-política de una comunidad indígena de Cajabamba - Chimborazo. En Ecuador Debate \# 12. Quito: CAAP.

10. Mencías, Jorge (1962). Riobamba (Ecuador): estudio de elevación socio cultural y religioso del indio. Friburgo (Suiza) y Bogotá (Colombia): Oficina Internacional de Investigaciones Sociales de FERES.

11. Sylva, Paola (1980). Sobrevivencia y disolución de un sector terrateniente serrano: caso de la Provincia de Chimborazo (1940-1979). Quito: FLACSO, tesis de maestría.
12. Tuaza, Luis Alberto (2009). "Cansancio organizativo". En Carmen Martínez, Repensando los movimientos indígenas. Quito: FLACSO, Ministerio de Cultura.

(2010). "Concepciones del esta-

do y demandas de las organizaciones campesinas e indígenas (1940-1969). En Transiciones y rupturas: el Ecuador en la segunda mitad del siglo XX, Felipe Burbano (Ed.): 465-513. Quito: FLACSO.

(2011a) "Desarrollo y etnicidad en los Andes centrales del Ecuador: Impactos en la organización indígena". En Etnicidad y desarrollo en los Andes, Pablo Palenzuela y AlessandraOlivi (Coordinadores): 83-123. Sevilla: Universidad de Sevilla, Secretariado de Publicaciones.

(2011b). Runakunakaashkashaikuskashinamirikurinkuna, ña mana tandanakunatamunankunachu: crisis del movimiento indígena ecuatoriano. Quito: FLACSO. 